\title{
In-out-in screws in femoral neck fractures: Can they be avoided?
}

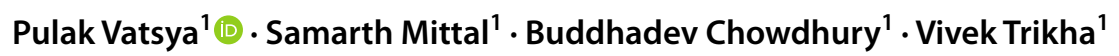

Received: 2 February 2021 / Accepted: 10 February 2021 / Published online: 18 February 2021

(c) The Author(s), under exclusive licence to Springer-Verlag France SAS part of Springer Nature 2021

The article by Yuan et al. [1] in your journal brings up a very important, but sparsely talked about issue encountered while doing screw fixation of femoral neck fractures. We ourselves have faced the problem of in-out-in screws in our practice over the years [2]. This letter intends to present a few insights into how we have analyzed this problem.

In the present study, CT scans were randomly done for non-orthopedic indications with no specific time periods after surgery which may not allow homogenous comparison of outcomes. Also, the most common cause of complications in neck of femur fractures is mal-reduction [3], which was not kept uniform amongst these patients. It is probably not right to compare outcomes especially nonunion or osteonecrosis of head with non-uniform reduction of these fractures.

Females constituted $74 \%$ of the patients in this present study. This may be a confounder in the study as it is known that female femoral necks are narrower than males, which can be a cause of higher number of in-out-in screws in this study [2,4]. Neck of femur fractures is also known to have posteromedial comminution due to the mechanism of injury [5]. A screw passing through such a comminuted fracture region may falsely appear as in-out-in on X-ray. CT scans, as also shown in the published images, have significant amount of scatter around metal hardware and thus cannot be used to ensure the in-out-in nature of these screws, especially with comminution when screws are very close to the cortex.

In our study, we found that an inverted triangle configuration has lower chances of bony perforation by the screw as compared to a non-inverted configuration. Also, we tend to use a smaller diameter posterior screw $(4.5 \mathrm{~mm}$ instead of $6.5 \mathrm{~mm}$ ) in females and in patients where we feel that the neck is narrow on pre-operative radiographs or CT scans. We did a CT-based study in our population to find that $75 \%$

Samarth Mittal

Samarthmittal@gmail.com

1 Department of Orthopedics, JPNATC, AIIMS, 409, Raj

Nagar, New Delhi 110029, India of the screws could be inserted in the safe bony corridor of the neck with $1 \mathrm{~mm}$ safety margin around the screw [2].

We would like to thank the authors for highlighting the importance of in-out-in screws. Every trauma orthopedic surgeon should be aware of this whenever operating on femoral neck fractures in order to avoid this complication. Sequential fluoroscopy, as advised by the authors, smaller posterior screws as well as adequate pre-operative radiographic planning are essential tools to avoid this complication.

Funding No funding was received from any source for this work.

\section{Compliance with ethical standards}

Conflict of interest The authors report no conflict of interest regarding this work.

\section{References}

1. Yuan BJ, Shamaa MT, Aibinder WR, Parry JA, Cross WW, Barlow JD et al (2020) High incidence of "in-out-in" posterosuperior screws after cannulated screw fixation of femoral neck fractures. Eur J Orthop Surg Traumatol 30(8):1417-1420

2. Trikha V, Kumar A, Mittal S, Passey J, Chouhan D, Dubey S (2020) Risk of bony violation with standard triple screw configurations for fixation of femoral neck fractures: a preliminary computed tomography based analysis. J Clin Orthop Trauma 1(11):S546-S552

3. Estrada LS, Volgas DA, Stannard JP, Alonso JE (2002) Fixation failure in femoral neck fractures. Clin Orthop Relat Res 399:110-118

4. Power J, Loveridge N, Kröger H, Parker M, Reeve J (2018) Femoral neck cortical bone in female and male hip fracture cases: differential contrasts in cortical width and sub-periosteal porosity in 112 cases and controls. Bone 1(114):81-89

5. Mittal R, Banerjee S (2012) Proximal femoral fractures: principles of management and review of literature. J Clin Orthop Trauma $3: 15-23$

Publisher's Note Springer Nature remains neutral with regard to jurisdictional claims in published maps and institutional affiliations. 